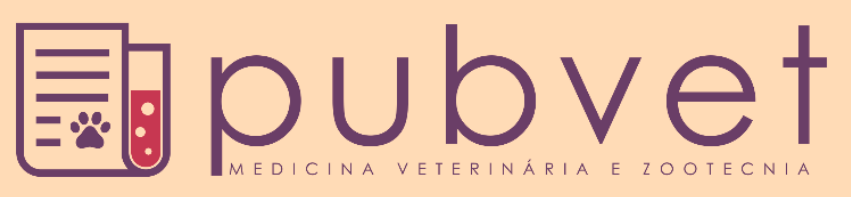

https://doi.org/10.31533/pubvet.v14n12a712.1-4

\title{
Histologia da cervix de ovelhas Santa Inês submetidas à técnica de inseminação por retração cervical
}

\author{
Caio Tácito Gomes Alvares ${ }^{1 *} \bullet$, Carla Cristina Romano ${ }^{2} \bullet$, Jurandir Ferreira da Cruz $^{30}$ \\ ${ }^{1}$ Professor da Universidade Estadual de Santa Cruz, Departamento de Ciências Agrárias e Ambientais, Ilhéus, Bahia, Brasil. \\ ${ }^{2}$ Professora da Universidade Estadual de Santa Cruz, Departamento de Ciências Biológicas, Ilhéus, Bahia, Brasil. \\ ${ }^{3}$ Professor da Universidade Estadual do Sudoeste da Bahia, Departamento de Fitotecnia e Zootecnia, Vitória da Conquista, Bahia, Brasil. \\ *Autor para correspondência, E-mail: ctgalvares@uesc.br
}

\begin{abstract}
Resumo. Este ensaio teve como objetivo avaliar a técnica de inseminação artificial por retração cervical (IRC) nos parâmetros histológicos da cervix de ovelhas da raça Santa Inês. Foram utilizadas três ovelhas pluríparas, cíclicas, quatro anos de idade, peso vivo 54,30 \pm $1,20 \mathrm{~kg}$ e escore de condição corporal 3,0, destinadas ao abate. Ao momento do estro, duas ovelhas foram submetidas à técnica de inseminação por retração cervical (IRC). Foram considerados três momentos distintos para abate das ovelhas: "0h", representado pela ovelha sem técnica IRC; " $24 h$ " e " 72 h" após a técnica IRC, abatendo-se as duas ovelhas nestes respectivos momentos. As cervix foram coletadas e preparadas para avaliação histológica. Os cortes histológicos demonstraram integridade tecidual ao momento do estro (sem IRC) e reação inflamatória intensa 24 horas após a IRC, com presença de hemorragia, edema e degeneração celular. Entretanto, foi observado que este quadro inflamatório se atenuou, com reorganização tecidual em até 72 horas.
\end{abstract}

Palavras chave: inflamação, reorganização tecidual, transcervical

\section{Histology of the cervix of Santa Inês ewes submitted to the technique of insemination by cervical retraction}

\begin{abstract}
This trial aimed to evaluate the technique of artificial insemination by cervical retraction (CRI) in the histological parameters of the cervix of Santa Inês sheep. Three pluriparous cyclical ewes were used, with four years old, live weight $54.30 \pm 1.20 \mathrm{~kg}$ and body condition score 3.0, at slaughter. At the time of estrus, two ewes were subjected to the insemination technique by cervical retraction (CRI). Three different moments were considered for the slaughter of the ewes: " $0 h$ ", represented by the non-CRI ewe; " $24 h$ " and " $72 \mathrm{~h}$ " after CRI technique, slaughtering the two ewes at these respective times. The cervix were collected and prepared for histological evaluation. Histological sections showed tissue integrity at the time of estrus ( $0 \mathrm{~h}$, without CRI) and an intense inflammatory reaction 24 hours after CRI, with the presence of hemorrhage, edema and cell degeneration. However, it was observed that this inflammatory condition was attenuated, with tissue reorganization within 72 hours.
\end{abstract}

Keywords: inflammation, tissue reorganization, transcervical

\section{Histología de la cervix de oveja Santa Inês sometida a la técnica de inseminación por retracción cervical}

Resumen. Este ensayo tuvo como objetivo evaluar la técnica de inseminación artificial por retracción cervical (IRC) en los parámetros histológicos de la cervix de ovejas Santa Inês. 
Se utilizaron tres ovejas pluríparas, cíclicas, de cuatro años de edad, peso vivo 54,30 $\pm 1,20$ $\mathrm{kg}$ y condición corporal 3,0, para el sacrificio. En el momento del estro, dos ovejas fueron sometidas a la técnica de IRC. Se consideraron tres momentos diferentes para el sacrificio de las ovejas: "0h", representado por la oveja sin técnica IRC; "24h" y "72h" después de la técnica IRC, sacrificando las dos ovejas en estos momentos respectivos. La cervix se recogió y se preparó para la evaluación histológica. Las secciones histológicas mostraron integridad tisular en el momento del estro ( $\sin$ IRC) y una reacción inflamatoria intensa 24 horas después de la IRC, con presencia de hemorragia, edema y degeneración celular. Sin embargo, se observó que esta condición inflamatoria se atenuó, con reorganización de los tejidos dentro de las 72 horas.

Palabras clave: Inflamación, reorganización de tejidos, transcervical

\section{Introdução}

A espécie ovina apresenta características anátomo-fisiológicas que limitam a popularização da inseminação artificial. O espermatozoide é susceptível a injúrias no processo de criopreservação, devido à maior sensibilidade da membrana à congelação, comprometendo a atividade respiratória, criocapacitação e interação com células do oviduto, diminuindo sua capacidade fecundante (Maxwell \& Salamon, 2000). No que se refere a fêmea, a cervix é longa, tubular e fibrosa, altamente tortuosa, com quatro a sete anéis desalinhados, que promovem barreira física contra contaminações externas. Mesmo em condições de estro, torna-se difícil a transposição desta estrutura, limitando a deposição uterina do sêmen (Kershaw et al., 2005).

O desenvolvimento de técnicas para inseminação transcervical permitiu maior frequência na deposição intrauterina do sêmen, no entanto, os resultados de fertilidade são muito variados, por influência de protocolos hormonais, número de partos, período de serviço e habilidade do inseminador. No Brasil foi criado um modelo curto de aplicador metálico contendo um mandril de ponta romba que permite a transposição cervical, de modo que, à retirada do mandril, realiza-se a introdução da palheta com a dose inseminante. Todavia, estudos em peças anatômicas revelaram que diferentes tipos de óstio cervical e interdigitações dos anéis podem interferir na penetrabilidade deste modelo de aplicador (Moura et al., 2011). Até mesmo a raça da ovelha pode influenciar nos resultados de penetrabilidade da cervix (Khalil et al., 2018).

Campbell et al. (1996) mensuraram via histologia o nível de lesão tecidual causado pela penetração cervical com uso de pipeta, identificando que as porções vaginais e medianas da cervix tendem a sofrer lesões epiteliais, consequentemente, reações inflamatórias. Dessa forma, este ensaio teve como objetivo avaliar a técnica de inseminação artificial por retração cervical (IRC) nos parâmetros histológicos da cervix em ovelhas Santa Inês.

\section{Material e métodos}

Os procedimentos experimentais utilizados neste estudo foram aprovados pela Comissão de Ética no Uso de Animais (protocolo $\mathrm{n}^{\circ}$ 68/14). O ensaio foi realizado na Estação Experimental Fazenda Almada/UESC, no Núcleo de Ovinocultura Tropical, Ilhéus, BA. Foram utilizadas três ovelhas da raça Santa Inês, pluríparas, cíclicas, quatro anos de idade, peso vivo 54,30 $\pm 1,20 \mathrm{~kg}$ e escore de condição corporal 3,0, destinadas ao abate. Ao momento do estro, duas ovelhas foram submetidas à técnica de inseminação por retração cervical (IRC). Esta técnica consistiu em utilizar um brete de contenção em estação com auxílio de uma tábua de apoio ventral, higienização da região vulvar, introdução de um espéculo vaginal de $15 \mathrm{~cm}$ com auxílio de fonte de luz para visualização do óstio cervical, retração da cervix até a abertura vulvar e fixação por meio de duas pinças Allis de $25 \mathrm{~cm}$ de comprimento e utilização do aplicador expansor metálico de $12 \mathrm{~cm}$ de comprimento contendo um mandril para transpor os anéis cervicais, tanto quanto possível. Foram considerados então três momentos distintos para abate das ovelhas: "0h", representado pela ovelha não submetida à técnica; "24h" e "72h" após a técnica IRC, abatendo-se as duas ovelhas nestes respectivos momentos. Para a avaliação histológica, as cervix foram seccionadas transversalmente, cortes foram incluídos em formaldeído a $10 \%$ por 36 horas e levados ao Laboratório de Histopatologia Veterinária da UESC, onde foram processados em banhos com álcoois e xilol e embebidos em parafina líquida. Os blocos moldados foram seccionados em micrótomo para 
confecção de lâminas, que foram desparafinadas, banhadas sequencialmente por xilol, álcoois e água destilada, e posteriormente coradas com hematoxilina e eosina (HE). A avaliação das lâminas foi realizada com microscópio óptico em aumentos de 100x e 400x.

\section{Resultados e discussão}

Os cortes histológicos demonstraram integridade tecidual ao momento do estro (sem IRC) e reação inflamatória intensa 24 horas após a técnica IRC, com presença de hemorragia, células inflamatórias (neutrófilos), edema e degeneração celular. Entretanto, após 72 horas, foi observado que este quadro inflamatório se atenuou, tendo pouca presença de linfócitos e ocorrendo reorganização tecidual (Figura 1).
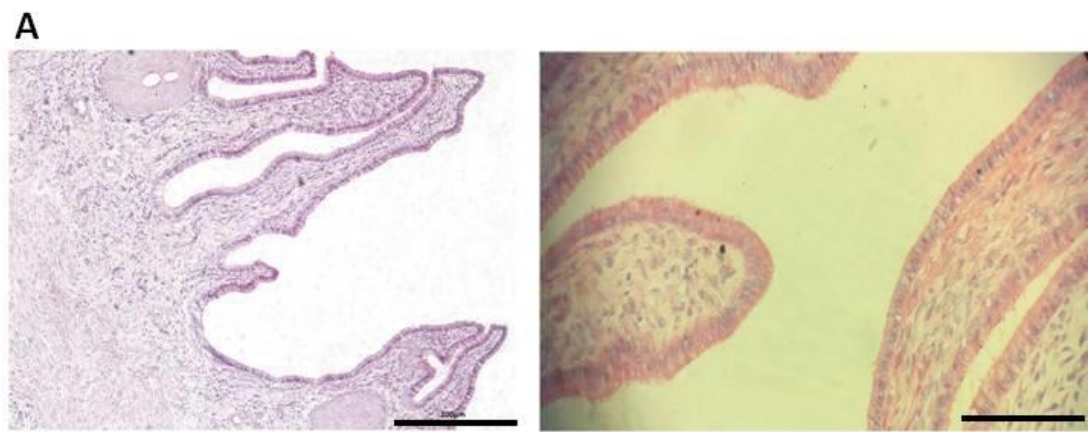

\section{B}
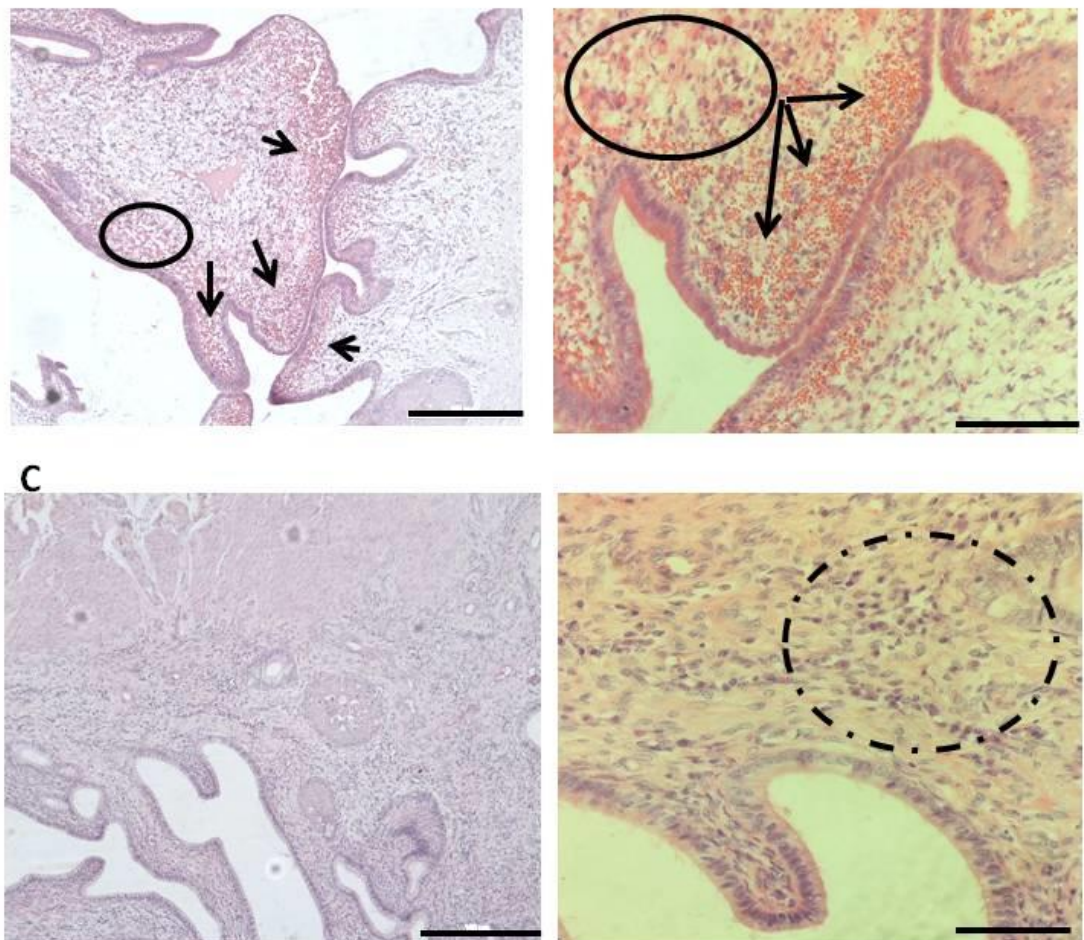

Figura 1. Histologia de cervix de ovelhas submetidas à técnica de inseminação artificial por retração cervical (IRC) em diferentes momentos (HE, microscopia óptica, à esquerda:

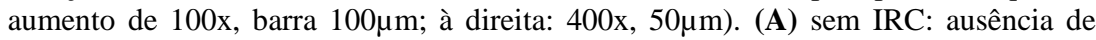
alterações teciduais; (B) 24h pós-IRC: focos de hemorragia intensa (setas); presença de células inflamatórias (neutrófilos) e edema/degeneração celular (área circundada); (C) 72h pós-IRC: poucas áreas com presença de linfócitos (plasmócitos, área pontilhada) e reorganização tecidual.

Wulster-Radcliffe \& Lewis (2002) desenvolveram um instrumento para manipular a cérvix de forma atraumática e demonstraram uma taxa de concepção de $50 \%$ ao $3^{\circ}$ dia pós IA. Entretanto, em estudo posterior com os mesmos instrumentos, foi observada taxa de gestação aos 30 dias de 5,0\%, sugerindo que a transposição da cérvix pode ocasionar perdas embrionárias por alteração de imunidade no ambiente uterino (Wulster-Radcliffe et al., 2004). 
A reação inflamatória local 24 horas após a manipulação da cervix era previsível, em função dos danos ao epitélio cervical que aplicadores podem proporcionar (Campbell et al., 1996; Sayre \& Lewis, 1997). Alguns autores sugerem que a manipulação e retração da cervix no momento da IA podem elevar a produção de $\mathrm{PGF}_{2 \alpha}$, provocando alterações no ambiente uterino pela migração de neutrófilos e citocinas $\mathrm{Th}_{1}$, com consequente luteólise e morte embrionária (Weems et al., 2006; Wulster-Radcliffe et al., 2004). Contudo, a reorganização tecidual em 72 horas sugere que as possíveis alterações inflamatórias decorrentes da técnica IRC estejam limitadas apenas ao canal cervical, o que poderia comprometer etapas anteriores a formação do corpo lúteo e desenvolvimento embrionário, como o transporte espermático e a fertilização, situação potencialmente agravada com o uso de sêmen congelado (Hawk, 1983; Sayre \& Lewis, 1997), resultando em baixas taxas de fertilidade.

\section{Conclusão}

A técnica de inseminação artificial por retração cervical pode provocar reação inflamatória na cervix, ocorrendo, contudo, recuperação tecidual em até 72 horas.

\section{Referências bibliográficas}

Campbell, J. W., Harvey, T. G., McDonald, M. F., \& Sparksman, R. I. (1996). Transcervical insemination in sheep: an anatomical and histological evaluation. Theriogenology, 45(8), 15351544. DOI: https://doi.org/10.1016/0093-691X(96)00121-5

Hawk, H. W. (1983). Sperm survival and transport in the female reproductive tract. Journal of Dairy Science, 66(12), 2645-2660. DOI: https://doi.org/10.3168/jds.s0022-0302(83)82138-9

Kershaw, C. M., Khalid, M., McGowan, M. R., Ingram, K., Leethongdee, S., Wax, G., \& Scaramuzzi, R. J. (2005). The anatomy of the sheep cervix and its influence on the transcervical passage of an inseminating pipette into the uterine lumen. Theriogenology, 64(5), 1225-1235. DOI: https://doi.org/10.1016/j.theriogenology.2005.02.017

Khalil, K. E., Allai, L., Fatet, A., Benmoula, A., Hamidallah, N., Badi, A., Moussafir, Z., Ibnelbachyr, M., \& El Amiri, B. (2018). Morphometry and depth of inseminating catheter penetration in prolific and non-prolific ewes at different ages: A post mortem study. Animal Reproduction Science, 196, 43-47. DOI: https://doi.org/10.1016/j.anireprosci.2018.06.017

Maxwell, W. M. C., \& Salamon, S. (2000). Storage of ram semen. Animal Reproduction Science, 62, 77-111. DOI: https://doi.org/10.1016/S0378-4320(00)00155-X

Moura, D. S., Lourenço, T. T., Moscardini, M. M., Scott, C., Fonseca, P. O., \& Souza, F. F. (2011). Aspectos morfológicos da cérvice de ovelhas. Pesquisa Veterinária Brasileira, 31, 33-38. DOI: https://doi.org/10.1590/s0100-736x2011001300006

Sayre, B. L., \& Lewis, G. S. (1997). Fertility and ovum fertilization rate after laparoscopic or transcervical intrauterine artificial insemination of oxytocin-treated ewes. Theriogenology, 48(2), 267-275. DOI: https://doi.org/10.1016/s0093-691x(97)84074-5

Weems, C. W., Weems, Y. S., \& Randel, R. D. (2006). Prostaglandins and reproduction in female farm animals. The Veterinary Journal, 171(2), 206-228. DOI: https://doi.org/10.1016/j.tvj1.2004.11.014

Wulster-Radcliffe, M. C., \& Lewis, G. S. (2002). Development of a new transcervical artificial insemination method for sheep: effects of a new transcervical artificial insemination catheter and traversing the cervix on semen quality and fertility. Theriogenology, 58(7), 1361-1371. DOI: https://doi.org/10.1016/s0093-691x(02)01042-7

Wulster-Radcliffe, M. C., Wang, S., \& Lewis, G. S. (2004). Transcervical artificial insemination in sheep: effects of a new transcervical artificial insemination instrument and traversing the cervix on pregnancy and lambing rates. Theriogenology, 62(6), 990-1002. DOI: https://doi.org/10.1016/j.theriogenology.2003.12.031

Histórico do artigo:

Recebido: 29 de junho, 2020 Aprovado: 21 de setembro, 2020. Disponível online: 5 de novembro, 2020 .
Licenciamento: Este artigo é publicado na modalidade Acesso Aberto sob a licença Creative Commons Atribuição 4.0 (CC-BY 4.0), a qual permite uso irrestrito, distribuição, reprodução em qualquer meio, desde que o autor e a fonte sejam devidamente creditados. 